\title{
Recent Developments in Pretreatment Technologies for Production of Lignocellulosic Biofuels
}

\author{
Bo Zhang* and Abolghasem Shahbazi
}

Biological Engineering Program, Department of Natural Resources and Environmental Design, North Carolina A \& T State University, 1601 East Market Street, Greensboro, NC 27411

\begin{abstract}
Rising oil prices and uncertainty over the security of existing fossil fuel reserves, combined with concerns over global climate change, have created the need for new transportation fuels and bioproducts to substitute for fossi carbon-based materials. Ethanol is considered to be the next generation transportation fuel with the most potential, and significant quantities of ethanol are currently being produced from corn and sugar cane via a fermentation process. Utilizing lignocellulosic biomass as a feedstock is seen as the next step towards significantly expanding ethanol production. The biological conversion of cellulosic biomass into bioethanol is based on the breakdown of biomass into aqueous sugars using chemical and biological means, including the use of hydrolotic enzymes. From that point, the fermentable sugars can be further processed into ethanol or other advanced biofuels. Therefore, pretreatment is required to increase the surface accessibility of carbohydrate polymers to hydrolytic enzymes. This paper reviews recent developments of several widely used pretreatment technologies, including alkali, hotwater, acid and inorganic salt (ionic liquid and Lewis acid) pretreatments. Recent advancements in the pretreatment field include: 1) application of novel chemicals or processes on biomass fractionation; 2) the use of new enzyme mixtures such ascombinations of purified xylan related enzymes, appreciation of soluble inhibitors of cellulases, and especially the evaluation of pretreated biomass at varying cellulase loading; 3 ) application of a wide variety of sophisticated techniques for analyzing native and pretreated biomass solids, especially microscopic techniques and methods for measuring surface area; and 4) greater efforts at scale up and commercialization of biomass processes for biofuels and chemicals.
\end{abstract}

Keywords: Pretreatment; Lignocellulosic Biofuels; Alkali; Hotwater; Acid; Ionic liquid; Lewis acid

\section{Introduction}

Rising oil prices and uncertainty over the security of existing fossil fuel reserves, combined with concerns over global climate change, have created the need for new transportation fuels and bioproducts to substitute for fossil carbon-based materials. Ethanol is considered next generation transportation fuel with the most potential, and significant quantities of ethanol are currently being produced from corn and sugar cane via a fermentation process. The use of lignocellulosic biomass as a feedstock is seen as the next step towards significantly expanding ethanol production capacity. Several biorefinery processes have been developed to produce biofuels and chemicals from biomass feedstock (Figure 1). There are two primary biorefinery platforms: the biological conversion route and the thermochemical route. In the thermochemical route, biomass is converted into syngas through gasification or into bio-oils through pyrolysis and catalytic hydrothermal treatment, which can be further upgraded to liquid fuels and other chemicals, such as menthol, gasoline, diesel fuel, and biodegradable plastics. While the biological route is based on the breakdown of biomass into aqueous sugars using chemical and biological means. The fermentable sugars can be further processed to ethanol or other advanced biofuels. However, in order to efficiently convert lignocellulosic biomass into bioethanol, technological barriers that include pretreatment, saccharification of the cellulose and hemicellulose matrixes, and simultaneous fermentation of hexoses and pentoses, still need to be addressed.

Pretreatment has been considered as the most expensive processing step in cellulosic ethanol processes, representing about $18 \%$ of the total cost [1-3]. Therefore, developing a cost-effective and efficient biomass pretreatment technology is the most critical need for lignocellulosic biofuels. Pretreatment is required to increase the surface accessibility of carbohydrate polymers to the hydrolytic enzymes, which is a key step toward efficient utilization of biomass for ethanol or other advanced biofuels production. Pretreatment enables enzymes to attach to the carbohydrate polymers, and then hydrolyze these polysaccharides into fermentable sugars. The goal of pretreatment is to pre-extract hemicellulose, disrupt the lignin seal and liberate the cellulose from the plant cell wall matrix (Figure 2)[4]. Depending on the application and type of pretreatment catalyst, pretreatment techniques have generally been divided into three categories: physical, chemical, and biological pretreatment. Each pretreatment method has its own advantages and disadvantages, and no single pretreatment approach is suitable for all biomass species.

Recent advancements in the pretreatment field include: 1) application of novel chemicals or processes on biomass fractionation; 2) the use of new enzyme mixtures such ascombinations of purified xylan related enzymes, appreciation of soluble inhibitors of cellulases, and especially the evaluation of pretreated biomass at varying cellulase loading; 3) application of a wide variety of sophisticated techniques for analyzing native and pretreated biomass solids, especially microscopic techniques and methods for measuring surface area; and 4) greater

*Corresponding author: Bo Zhang, Department of Natural Resources and Environmental Design, North Carolina A \& T State University, 1601 East Marke Street, Greensboro, NC 27411,Tel: 336-334-7787; Fax: 336-334-7270; E-mail: bzhang@ncat.edu

Received April 08, 2011; Accepted June 22, 2011; Published June 24, 2011

Citation: Zhang B, Shahbazi A (2011) Recent Developments in Pretreatment Technologies for Production of Lignocellulosic Biofuels. J Pet Environ Biotechnol 2:108. doi:10.4172/2157-7463.1000108

Copyright: ( 2011 Zhang B, et al. This is an open-access article distributed unde the terms of the Creative Commons Attribution License, which permits unrestricted use, distribution, and reproduction in any medium, provided the original author and source are credited. 


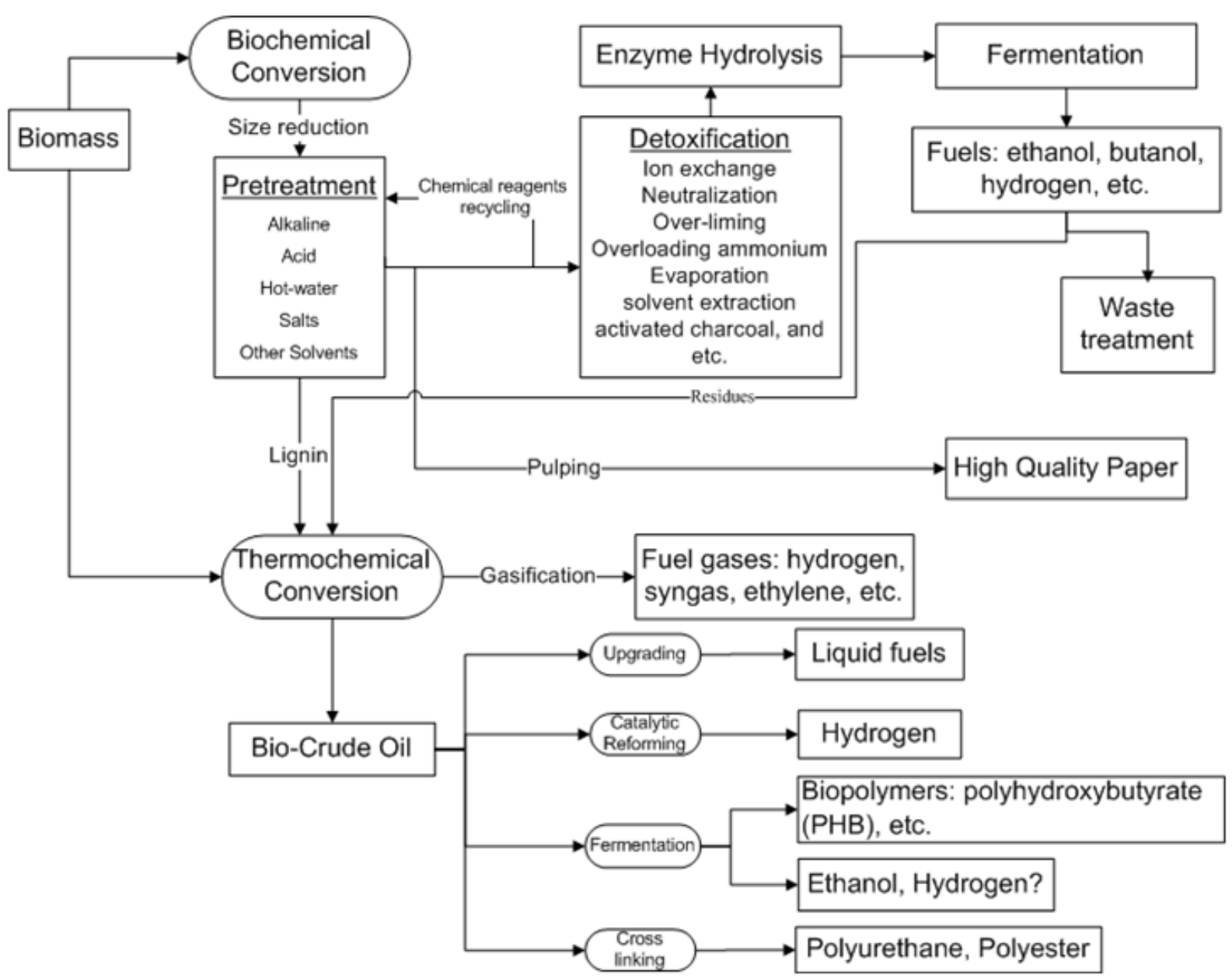

Figure 1: Biorefinery options

efforts at scale up and commercialization of biomass processes for biofuels and chemicals. The processes of pretreatment have previuously been reviewed $[2,3,5,6]$, and this paper reviews recent developments of several widely used pretreatment technologies, including alkali, hotwater, acid and inorganic salt pretreatments.

\section{Alkaline pretreatment}

Using alkaline chemicals such as dilute sodium hydroxide, aqueous ammonia and lime to remove lignin has long been known to improve cellulose digestibility [7]. Commercially, DuPont-Danisco has developed a proprietary mild alkaline pretreatment process through its collaboration with the US. Department of Energy National Renewable Energy Lab (NREL) [8].

\section{Sodium hydroxide $(\mathrm{NaOH})$}

Among the alkaline reagents, sodium hydroxide $(\mathrm{NaOH})$ was widely used for pretreatment because its alkalinity is much higher than others. Zhang et al. [9] reported that $54.8 \%$ of cattail lignin and $43.7 \%$ of the hemicellulose were removed when applying a $4 \% \mathrm{NaOH}$ solution. The overall effectiveness of alkali pretreatment was found to be a function of $\mathrm{NaOH}$ concentration. Nearly $78 \%$ of the cellulose from raw cattails was converted to fermentable glucose in $48 \mathrm{~h}$ using a cellulase loading of $60 \mathrm{FPU} / \mathrm{g}$ glucan.
Adding additional chemicals with $\mathrm{NaOH}$ could improve the pretreatment performance. For instance, by combining $5 \% \mathrm{NaOH}$ with a $5 \% \mathrm{H}_{2} \mathrm{O}_{2}$ solution that helps in additional lignin removal by oxidative action on lignin, the maximum overall sugar yield obtained from high lignin hybrid poplar pretreated at $80^{\circ} \mathrm{C}$ was $80 \%$ [10]. When spruce wood chips were pretreated with a $\mathrm{NaOH} /$ urea mixture solution, a $70 \%$ glucose yield was obtained at the low temperature of $\left(-15^{\circ} \mathrm{C}\right)$ using $7 \%$ $\mathrm{NaOH} / 12 \%$ urea solution, however, only $20 \%$ and $24 \%$ glucose yields were obtained at temperatures of $23^{\circ} \mathrm{C}$ and $60^{\circ} \mathrm{C}$, respectively [11] SEM confirmed that the $\mathrm{NaOH} /$ urea pretreatment could disrupt the bonds between hemicelluloses, cellulose, and lignin, and thus change the structure of cellulosic material. Partial lignin, hemicelluloses and cellulose was removed from spruce, enhancing the enzymatic hydrolysis efficiency of the lignocellulosic biomass.

The enzyme kinetics of sodium hydroxide pretreated biomass (wheat straw) were studied via two theoretical approaches, which describe the influence of enzyme concentration $(6.25-75 \mathrm{~g} / \mathrm{L})$ on the production of reducing sugars [12]. The first approach used a modified Michaelis-Menten equation to determine the hydrolysis model and kinetic parameters (maximal velocity, Vemax, and half-saturation constant, $\mathrm{Ke}$ ). The second approach, the Chrastil approach, was used to study all the time values from the rate of product formation. This approach considers that the product formation reactions are diffusion 


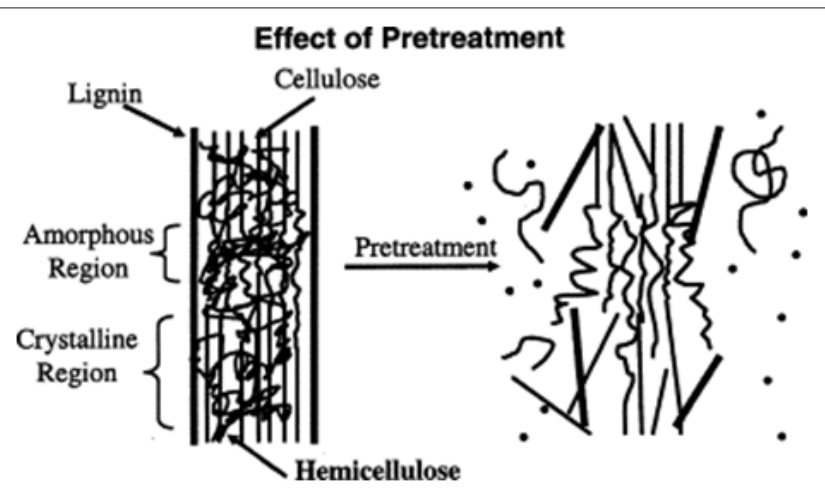

Figure 2: Schematic of goals of pretreatment on lignocellulosic material .

limited, and the time curves are dependent on the structure of the heterogeneous enzyme systems.

Compared to other pretreatment technologies, alkali pretreatment usually does not require high temperatures and high pressures, so the cost of pretreatment equipment is significantly low. However, pretreatment time is in the range of hours to days. Sodium hydroxide is expensive, and the recovery process is complex. Another challenge of alkaline pretreatment is the neutralization of alkali, which forms significant amount of salts.

\section{Lime}

Lime pretreatment has the following advantages: lime is the least expensive alkali at $\$ 0.06 / \mathrm{kg}$; is safe to handle; and can be simply recovered [13]. The mechanism is similar to the $\mathrm{NaOH}$ pretreatment. When using over lime $\left(0.5 \mathrm{~g} \mathrm{Ca}(\mathrm{OH})_{2} / \mathrm{g}\right.$ biomass $)$ to pretreat corn stover at $25-55^{\circ} \mathrm{C}$, lignin and hemicellulose were selectively removed, the degree of crystallinity slightly increased from $43 \%$ to $60 \%$ with delignification, but cellulose was not affected [14]. Lime pretreatment technology has been thoroughly studied on various biomass sources, such as sugarcane bagasse [15], switchgrass [16] and poplar [17].

Sierra et al. [17] combined the lime pretreatment with highpressure oxygen, and found that the digestibility of poplar wood was significantly increased $[18,19]$. Poplar was treated with $0.18-0.39 \mathrm{~g}$ lime/g biomass at $140-160^{\circ} \mathrm{C}$ for $2 \mathrm{hr}$ under $14.8-21.7$ bar absolute. The overall glucose and xylose yields obtained under these recommended conditions were $\sim 95 \%$ and $\sim 73.1 \%$, respectively.

Lime provides a lower cost alternative than other alkalis, and lime pretreatment also requires lower temperatures and pressures. As with the $\mathrm{NaOH}$ pretreatment, the drawbacks of the lime pretreatment are long residence time, a large amount of wash water, or time consuming neutralization process and the formation of large quantities of salts, such as $\mathrm{Ca}(\mathrm{SO})_{4}$.

Terrabon, Inc. (www.terrabon.com) licensed the MixAlco technology from Texas A\&M University. The MixAlco process consists of a lime pretreatment followed by fermentation by microorganisms, producing a mixture of carboxylic acids, such as acetic, propionic or butyric acids. Calcium carbonate is added to neutralize the acids and form their corresponding carboxylate salts, such as calcium acetate, propionate and butyrate. The salts can be dewatered, concentrated, dried and thermally converted to ketones such as acetone, which can be hydrogenated to produce secondary alcohols such as isopropanol, propanol and butanol; or the carboxylic acids can be recovered from the fermentation solution by reacting with tertiary amines to form tertiary amine carboxylates and calcium carbonate that are then cracked to regenerate the tertiary amine and produce the carboxylic acids. According to the company, those primary or secondary alcohols can then be oligomerized to produce gasoline, diesel or jet fuel. According to Terrabon, the tertiary amine and calcium carbonate are recycled within the process so no chemicals are consumed. However, the cost of recycling $25 \%$ of calcium carbonate via lime kiln is expensive.

\section{Ammonia fiber expansion (AFEX)}

During an ammonia fiber expansion/explosion, biomass particles are rapidly heated by high-pressure ammonia for a period time, then the pretreatment process is terminated by rapidly releasing pressure, which causes the biomass to undergo an explosive decompression. Ninety-nine percent of the ammonia is recovered and reused, while the remainder serves as a downstream nitrogen source for fermentation. The AFEX process decrystallizes cellulose, depolymerizes hemicellulose, and depolymerizes and removes lignin from cellulose/ hemicellulose. The ammonia fiber expansion/explosion (AFEX) process has been found to be an effective pretreatment for promoting enzymatic hydrolysis of a wide variety of biomass sources, including corn stover [20], switchgrass [21], coastal Bermuda grass [22], forage and sweet sorghum bagasse [23]. The AFEX-treated hemicellulose is in oligomeric form, which can usually be hydrolyzed to fermentable pentoses by most commercial cellulase and xylanase mixtures.

AFEX treatment parameters include temperature, moisture content, ammonia loading and residence time. Teymouri et al. [20] optimized the AFEX pretreatment process for corn stover. The reactivity of pretreated biomass was affected by all operation variables including temperature, moisture content, ammonia loading and treatment time. Under the optimal conditions the glucose yield was close to the theoretical value, and the xylose yield was $\sim 80 \%$, using $60 \mathrm{FPU}$ of cellulase enzyme/g of glucan. They concluded that AFEX is a promising pretreatment technology because of low enzyme requirements, the absence of degradation products, and much higher solids loadings.

Recently, Lee et al. [22] compared the autohydrolysis with AFEX pretreatments using coastal Bermuda grass as the feedstock. An AFEX pretreatment of $\left(100^{\circ} \mathrm{C}\right.$ for $\left.30 \mathrm{~min}\right)$ and an autohydrolysis pretreatment $\left(170^{\circ} \mathrm{C}\right.$ for $\left.60 \mathrm{~min}\right)$ resulted in a sugar yield of $94.8 \%$ and $55.4 \%$, respectively, when applying a enzymatic loading of $30 \mathrm{FPU} / \mathrm{g}$. AFEX pretreatment did not change the chemical composition of coastal Bermuda grass, but caused re-localization of lignin components. Bals et al. [24] studied the effectiveness of ammonia fiber expansion pretreatment on two harvest times and locations for switchgrass, and suggested that both harvest date and ecotype/location would determine the optimal pretreatment conditions.

\section{Ammonia recycle percolation}

Ammonia Recycle Percolation (ARP) is a process that pretreats biomass with 5-15 wt\% aqueous ammonia in a flow-through column reactor. Ammonia, being a selective reagent for lignin, noncorrosive, and a relatively less expensive chemical, is an appropriate choice for pretreatment. SEM and FTIR spectra showed that the aqueous ammonia causes swelling and delignification of biomass at high temperatures. The ARP process could solubilize $~ 50 \%$ xylan from corn stover, but retains over $92 \%$ of the cellulose. Enzymatic digestibility of ARP-treated corn stover is $93 \%$ with $10 \mathrm{FPU} / \mathrm{g}$-glucan enzyme loading [25]. The X-ray crystallography data showed that the basic cellulosic crystalline structure was not altered. By further minimizing 
the liquid throughput and optimizing the operation conditions for corn stover, $59-70 \%$ of lignin removal and $48-57 \%$ of xylan retention were achieved. Enzymatic digestibilities were 95,90 , and $86 \%$ with 60 , 15 , and 7.5 FPU/g of glucan, respectively [26]. ARP also showed great success in the delignification of sorghum [27], poplar [28], switchgrass [29] etc.

In order to reduce liquid loadings of the ARP process and make the process more cost effective, the soaking in aqueous ammonia (SAA) at low temperature - which retains the hemicellulose in the solids by minimizing the interaction with hemicellulose during treatment - was reported as a feasible approach to increase the fermentation yield and simplify the bioconversion scheme [30,31].

\section{Hot-Water Pretreatment}

Hot water pretreatment is often called "autohydrolysis." The major advantages of this method are less expense, lower corrosion to equipment, less xylose degradation and thus fewer byproducts including inhibitory compounds in the extracts [32]. Hot water under pressure can penetrate the cell structure of biomass, hydrate cellulose, and remove hemicellulose, thus effectively improving the enzymatic digestibility of biomass cellulose. A pretreatment at $190^{\circ} \mathrm{C}$ for more than 10 minutes could effectively dissolve the xylan fraction of aquatic plant cattail as soluble oligomers. Both the glucose yield and xylose yield obtained from the pretreated cattail increased with the escalation of the final pretreatment temperature and treatment time. When cattails were pretreated at $190^{\circ} \mathrm{C}$ for 15 minutes, the highest glucose yield of $77.6 \%$ from the cellulose was achieved in $48 \mathrm{~h}$ using a cellulase loading of $60 \mathrm{FPU} / \mathrm{g}$ glucan [33]

At optimal conditions, $90 \%$ of the cellulose from corn stover pretreated in hot-water can be hydrolyzed to glucose [34]. The pretreatment process of bagasse was studied over a temperature range of $170-203^{\circ} \mathrm{C}$, and time range of $1-46 \mathrm{~min}$. An $80 \%$ conversion yield was achieved, and no hydrolysis inhibitors were detected [35]. Hot water pretreatment was also reported to improve enzymatic digestibility of switchgrass, resulting in an $80 \%$ glucose yield [36]. The optimal hotwater pretreatment conditions for hybrid poplar consisting of of $15 \%$ solids (wt/vol) were $200^{\circ} \mathrm{C}$ for $10 \mathrm{~min}$, which resulted in the highest fermentable sugar yield, in the range of $54 \%$ and $67 \%$ [37].

Inbicon Biomass Refinery at Danmark established a demonstration facility based on hot-water pretreatment technology. Their goal is to demonstrate 4 ton $/ \mathrm{hr}$ of continuous operation at industrial scale by 2013 [38].

\section{Acid Pretreatment}

The use of acid hydrolysis for the conversion of cellulose to glucose is a process that has been studied for the last 100 years. Generally, there are two types of acid hydrolysis: dilute and concentrated, each having unique properties and effects on biomass, and each having advantages and disadvantages in terms of economics

\section{Dilute-acid pretreatment}

Dilute acid (0.5-1.0\% sulfuric acid) pretreatment at moderate temperatures $\left(140-190^{\circ} \mathrm{C}\right)$ can effectively remove and recover most of the hemicellulose as dissolved sugars. In the process, lignin is disrupted and partially dissolved, thus increasing cellulose susceptibility to enzymes [39]. Under this method, glucose yields from cellulose increase with hemicellulose removal to almost 100\% [40]. Dilute acid hydrolysis consists of two chemical reactions. One reaction converts cellulosic materials to sugar and the other converts sugars into other chemicals, many of which inhibit the growth of downstream fermentation microbes. The same conditions that cause the first reaction to occur, simultaneously cause over-degradation of sugars and lignin, creating inhibitory compounds such as organic acids, furans, and phenols.

Partial cellulose may be degraded as oligomers or monomers during the acid pretreatment process. Sugar (glucose and xylose) yields were often reported for the pretreatment and enzyme hydrolysis stage separately, and as the total for both stages. Lloyd and Wyman [41] reported that up to $92 \%$ of the total sugars originally available in corn stover could be recovered via coupled dilute acid pretreatment and enzymatic hydrolysis. Conditions achieving maximum individual sugar yields were often not the same as those that maximized the total sugar yields, demonstrating the importance of clearly defining pretreatment goals when optimizing the process.

Dilute sulfuric acid pretreatment has been applied to a number of feedstocks including aquatic plants [42], switchgrass [43], hardwood [44], softwood [45], etc. The dilute-sulfuric acid pretreatment is an effective pretreatment approach that results in a high sugar yield from most biomass feedstocks. The disadvantages of the dilute sulfuric acid pretreatment are 1) corrosivity, requiring expensive construction materials, 2) formation of inhibitory compounds, 3) the requirement for acid neutralization.

Verenium (www.verenium.com) is using a combination of acid pretreatments, enzymes, and two types of bacteria to make ethanol from bagasse that's left over from processing sugarcane to make sugar. It will also process "energy cane", a relative of sugarcane that's lower in sugar and higher in fiber. The high fiber content allows the plants to grow taller, increasing yield from a given plot of land.

\section{$\mathrm{SO}_{2}$-Catalyzed steam explosion}

$\mathrm{SO}_{2}$ impregated steam-explosion has been considered as one of the most cost-effective pretreatment processes. Similar to the AFEX pretreatment, an $\mathrm{SO}_{2}$ catalyst is used to presoak the biomass before a steam-explosion pretreatment. $\mathrm{SO}_{2}$ steam-explosion promotes hemicellulose hydrolysis and increases the reactivity of various biomasses.

For example, when corn fiber was exposed to $3 \% \mathrm{SO}_{2}$, and then pretreated at $190^{\circ} \mathrm{C}$ for 5 minutes, coupled $\mathrm{SO}_{2}$-catalyzed steam explosion and enzymatic hydrolysis resulted in a maximum conversion efficiency of $81 \%$ of the combined original hemicellulose and cellulose $[46,47]$. An $\mathrm{SO}_{2}$-catalyzed steam explosion could effectively increase the saccharification efficiencies of softwoods [48]. However, even with optimized steam pretreatment conditions, delignification after pretreatment was necessary in order to obtain sufficient hydrolytic conversion and subsequent fermentability [49].

An improved saccharification of $\mathrm{SO}_{2}$ catalyzed steam-exploded corn stover was observed by adding polyethylene glycol (PEG6000). Adding PEG6000 could lower the enzyme loading and facilitate desorption of enzyme protein from lignocellulose. With $20 \%$ solid loading, the highest glucose concentrations of $102 \mathrm{~g} / \mathrm{L}$ and $91.3 \%$ sugar yield were obtained [50].

In summary, $\mathrm{SO}_{2}$ catalyzed steam-explosions has been tested at pilot-scale [51], and showed high efficiency on the pretreatment of soft woods. However, in order to obtain complete hydrolysis of the cellulosic component at reduced enzyme loadings, a delignification step is still required. At the same time, $\mathrm{SO}_{2}$ is highly toxic and may cause unsafe impacts on heath and environment. Also, some inhibitors 
are derived from the degradation of carbohydrates during the catalyzed steam-explosion process.

In 2010, Mascoma (www.mascoma.com), which has spent the past five years developing its consolidated bioprocessing (CBP) technology, acquired Canada's SunOpta BioProcess Inc., a division of SunOpta Inc. SunOpta's steam explosion technology is a first-step pretreatment process which exposes the cellulosic fibers of various materials, including woody biomass, switchgrass or agricultural waste, for further conversion to biofuels. Another commerical cellulsic ethanol company Abengoa Bioenergy/Iogen, is also using an acid steam explosion pretreatment process [52].

\section{Concentrated acid hydrolysis}

The concentrated acid process for producing sugars and ethanol from lignocellulosic biomass has a long history that goes back to1883. Concentrated acid hydrolysis (about $70 \%$ acid content) uses a low temperature $\left(100^{\circ} \mathrm{F} / 38^{\circ} \mathrm{C}\right)$ and low pressure. The rate of cellulose recovery from the initial pre-treatment process and the conversion rate of cellulose to glucose under this process are much higher (90\%) than with dilute acid hydrolysis. One concentrated acid hydrolysis model was developed by USDA and further refined by Purdue University and the Tennessee Valley Authority (TVA) [53]. Among the improvements added by these researchers were 1) recycling of dilute acid from the hydrolysis step and reusing it in the hemicellulose pretreatment step and 2) improved recycling of sulfuric acid by the use of a chromatographic column. Minimizing the use of sulfuric acid and recycling the acid costeffectively are critical factors in the economic feasibility of the process.

The primary advantage of the concentrated process is the high sugar recovery efficiency, which can be on the order of more than $90 \%$ of both hemicellulose and cellulose sugars [54]. The low temperatures and pressures employed also allow the use of relatively low cost materials, such as fiberglass tanks and piping. The weaknesses, compared to other processes, are its relatively slow rate of conversion, and the fact that more economical and efficient acid recovery systems need to be developed. Unless the acid is removed, large quantities of lime must be used to neutralize the sugar solution, which requires the disposal of salts. This increases the cost and makes the end product more expensive.

BlueFire Ethanol Incorporated (www.bluefireethanol.com) in the United States is currently working with DOE to commercialize this technology. BlueFire Ethanol Incorporated uses the Arkenol patented process, and it's a viable, world-wide cellulose-to-ethanol company with demonstrated production experience with ethanol from wood wastes, urban trash (post-sorted MSW), rice and wheat straws and other agricultural residues. To demonstrate the efficacy of the technology, the company has constructed and operated a pilot plant near its southern California offices for roughly eight years since 2003. BlueFire is building its second biorefinery plant at Fulton, MS.

Meanwhile, HCL CleanTech (www.hclcleantech.com) uses concentrated hydrochloric acid $(\mathrm{HCl})$ technology, which efficiently hydrolyzes all cellulosic materials and so allows a large variety of feedstock to be used with minimal configuration. HCL CleanTech announced that cost of the sugars produced by HCL CleanTech is more than $17 \%$ lower than the cost of corn mill sugars, while their quality is very similar. HCL CleanTech's process is more than $80 \%$ environmentally friendlier than corn mill processes by a Life Cycle Analysis comparison. In June 2010, HCL CleanTech has begun running its first pilot plant at the Southern Research Institute, NC.

\section{Inorganic Salts Pretreatment}

\section{Ionic liquid}

An ionic liquid (IL) is a salt in the liquid state with a melting point typically below $100^{\circ} \mathrm{C}\left(212^{\circ} \mathrm{F}\right)$. ILs are largely composed of ions and short-lived ion pairs, and developed as environmentally friendly alternative to organic solvents. Because of their extremely lowvolatility, ILs are expected to have minimal environmental impact as a pretreatment reagent. ILs have been shown to be highly effective at solvating cellulose to technically useful concentrations [55]. During IL pretreatment, the microcrystalline cellulose is first dissolved and then recovered as essentially amorphous or as a mixture of amorphous and partially crystalline cellulose by rapidly quenching the solution with an antisolvent.

Graenacher first suggested in 1934 that molten N-ethylpyridinium chloride in the presence of nitrogen-containing bases, which have a relatively high melting point of $118^{\circ} \mathrm{C}$, could be used to dissolve cellulose, followed by subsequent chemical and mechanical processing [56].

Several ionic liquids containing 1-butyl-3-methylimidazolium cations $\left([\mathrm{C} 4 \mathrm{mim}]^{+}\right)$that would dissolve cellulose have been screened [55]. It has been shown that these ILs can be used as non-derivatizing solvents for cellulose, and ILs incorporating anions as hydrogen bond acceptors were the most effective, whereas ILs containing 'non coordinating' anions, including [BF4] ${ }^{-}$and [PF6] were nonsolvents. Chloride containing ILs appear to be the most effective solvents, presumably solubilizing cellulose through hydrogen-bonding from hydroxyl functions to the anions of the solvent.

Li et al. [57] compared dilute acid pretreatment of switchgrass with ionic liquid [C2mim] [OAc] pretreatment in terms of delignification, saccharification efficiency and reducing sugar yields. During ionic liquid pretreatment, switchgrass cellulose undergoes dissolution and precipitation by an anti-solvent, resulting in reduced cellulose crystallinity and increased surface area, and a glucan yield of $96.0 \%$. Lignin removal by IL is more effective than that of acid pretreatment.

Dadi et al. [58] studied the saccharification kinetics of cellulose pretreated using an ionic liquid: 1-n-butyl-3-methylimidazolium chloride. The initial enzymatic hydrolysis rates were approximately 50-fold higher for regenerated cellulose as compared to untreated Avicel PH-101 cellulose. They [59] further compared the effect of two ILs: 1-n-butyl3-methylimidazolium chloride (BMIMCl) and l-allyl-3-methylimidazolium chloride (AMIMCl). By optimizing the IL treatment conditions, the digestibility of the IL-treated cellulose is significantly enhanced, and the initial hydrolysis rates were up to 90 times greater than those of untreated cellulose.

In order to select inexpensive, efficient and environmentally sound solvents for processing cellulosic biomass, Zhao et al. [60] studied a number of chloride- and acetate-based ILs for cellulose regeneration. Their data suggested that all regenerated celluloses are less crystalline (58-75\% lower), and the initial hydrolysis rates were 2-10 times faster than the respective untreated celluloses.

The mechanism of the IL pretreatment was visualized using different technologies. Poplar wood was swollen by ionic liquid (1-ethyl-3methylimidazolium acetate) pretreatment at room temperature [61], and silver and gold nano-particles of diameters ranging from 20 to $100 \mathrm{~nm}$ were able to be incorporated at depths up to $4 \mu \mathrm{m}$. Confocal surface-enhanced Raman images and Quantitative X-ray fluorescence microanalyses confirmed the incorporation of these nano-particles. 


\begin{tabular}{|c|c|c|}
\hline Methods & Features and Advantages & Disadvantages \\
\hline Sodium hydroxide $(\mathrm{NaOH})$ & remove lignin, low temperature and pressure, & $\begin{array}{l}\text { inhibitory, long pretreatment time, expensive chemical, } \\
\text { complex recovery process }\end{array}$ \\
\hline Lime & the least expensive alkali; safe to handle; can be simply recovered & $\begin{array}{l}\text { inhibitory, long residence time, neutralization or washing } \\
\text { process required }\end{array}$ \\
\hline Ammonia fiber expansion (AFEX) & $\begin{array}{l}\text { low enzyme requirement, minimized degradation products, high solids } \\
\text { loadings }\end{array}$ & $\begin{array}{l}\text { formation of oligomeric form of hemicellulose degradation } \\
\text { products }\end{array}$ \\
\hline Ammonia recycle percolation (ARP) & high efficiency for delignification, & low solids loadings \\
\hline Hot-water & low cost, less inhibition, low corrosion, less residues, high simplicity & $\begin{array}{l}\text { high temperature, particle size reduction required to } \\
\text { obtain high yield }\end{array}$ \\
\hline Dilute sulfuric acid & high yield & inhibitory, causticity reagent, acid neutralization required \\
\hline $\mathrm{SO}_{2}$-catalyzed steam explosion & high solids loadings, rapid penetration of biomass & highly toxic, inhibitory \\
\hline Concentrated acid hydrolysis & high yield & slow rate of conversion, acid recovery systems required \\
\hline Ionic liquid & effective at solvating cellulose, minimal environmental impact & $\begin{array}{l}\text { high cost, induction of cellulase inactivation; effective } \\
\text { regeneration; causticity and toxicity of ILs; selection of } \\
\text { stable ILs }\end{array}$ \\
\hline Lewis acid & lower corrosion to equipment, lower enzyme demands & $\begin{array}{l}\text { overall efficiency needs to be improved, the effect of } \\
\text { Lewis acid residues on the downstream processing need } \\
\text { to be evaluated }\end{array}$ \\
\hline
\end{tabular}

Table 1: Simple comparison of different pretreatments.

Auto-fluorescent mapping of switchgrass cell walls was used to visualize the mechanisms of biomass dissolution during ionic liquid pretreatment [62]. Treating switchgrass in the ionic liquid of 1-n-ethyl-3-methylimidazolium acetate resulted in the disruption and solubilization of the plant cell wall at mild temperatures. The results showed that swelling of the plant cell wall, attributed to disruption of inter- and intramolecular hydrogen bonding between cellulose fibrils and lignin, was followed by complete dissolution of the biomass.

Application of ionic liquids for the lignocellulosic biomass fractionation or pretreatment is still in its infancy. Most studies were done using cellulose. There are still multiple challenges needed to be overcome before applying this new concept in the field. Some of these challenges include the high cost of ILs; induction of cellulase inactivation; effective regeneration; causticity and toxicity of ILs; selection of stable ILs with suitable physical properties; and process scale-up.

\section{Lewis acid}

Lewis acid is defined as a molecular entity that is an electronpair acceptor and therefore able to react with a Lewis base to form a Lewis adduct by sharing the electron pair furnished by the Lewis base. A typical example of a Lewis acid in action is in the Friedel-Crafts alkylation reaction [63]. The key step is the acceptance by $\mathrm{AlCl}_{3}$ of a chloride ion lone-pair, forming $\mathrm{AlCl}_{4}^{-}$and creating the strongly acidic, that is to say, electrophilic, carbonium ion.

Recently, it has been discovered that Lewis acid, specially chloride salts, can react with cellulosic biomass directly, in an aqueous phase or in ionic liquid with excellent selectivity $[64,65]$. Liu and Wyman [66] evaluated the effect of several inorganic salts $\mathrm{KCl}, \mathrm{NaCl}, \mathrm{CaCl}_{2}$, $\mathrm{MgCl}_{2}$, and $\mathrm{FeCl}_{3}$ on xylose monomer and xylotriose degradation. $\mathrm{FeCl}_{3}$ was found to significantly increase xylose monomer and xylotriose degradation, resulting in degradation ratio of $65 \%$ and $78 \%$ for xylose and xylotriose, respectively. Also, losses of xylose and xylotriose were described using first order homogeneous kinetics. Yu et al. [67] investigated the effect of the metal salts $\mathrm{NaCl}, \mathrm{KCl}, \mathrm{CaCl}_{2}$, $\mathrm{MgCl}_{2}, \mathrm{FeCl}_{3}, \mathrm{FeCl}_{2}$, and $\mathrm{CuCl}_{2}$ solutions on the decomposition of sweet sorghum bagasse. The hemicellulose removal by using transition metal chlorides is higher than that of using the alkaline earth metal chlorides or alkaline metal chlorides. Chloride salts may react with biomass, forming a saccharide-metal cation intermediate complex. The total sugar yield from sweet sorghum bagasse undergoing a $0.1 \% \mathrm{CuCl}_{2}$ solution pretreatment reached $90.4 \%$.

Liu et al. [68] used $\mathrm{NaCl}, \mathrm{KCl}, \mathrm{CaCl}_{2}, \mathrm{MgCl}_{2}, \mathrm{FeCl}_{2}, \mathrm{FeSO}_{4}$, $\mathrm{FeCl}_{3}$, and $\mathrm{Fe}_{2}\left(\mathrm{SO}_{4}\right)_{3}$, as catalysts for the degradation of corn stover hemicellulose. Under optimal conditions of $0.1 \mathrm{M} \mathrm{FeCl}_{3}$ at $140^{\circ} \mathrm{C}$ for 20 min, the xylose recovery yield and cellulose removal amount were $90 \%$ and $<10 \%$, respectively. They further optimized a $\mathrm{FeCl}_{3}$ pretreatment process of corn stover for cellulose conversion [69]. The optimum yield of $98.0 \%$ was obtained. FTIR, SEM and XRD analysis indicated that $\mathrm{FeCl}_{3}$ pretreatment may damage the surface of corn stover and disrupt almost all the ether linkages and some ester linkages between lignin and carbohydrates, but have no effect on delignification by analysis.

The advantages of the Lewis acid pretreatment include the lower corrosion to equipment frommetal chlorides and lower xylanase demand for hydrolysis. However, the mechanism of Lewis acid pretreatment is not clear, the overall efficiency of the pretreatment needs to be improved, and the effect of Lewis acid residues on the downstream processing needs to be evaluated.

\section{Other Commercial Pretreatment Technologies}

Several lignocellulose-based ethanol demonstration plants are operating in the US, though there still exists technical, economical, and commercial barriers. The pretreatment techology used by some of these cellulosic ethanol companies were reviewed above. Some of them do not use pretreatment or do not talk about their methods for pretreatment of cellulose. The following two commercial cellulosic ethanol companies use different pretreatement approaches.

PureVision (www.purevisiontechnology.com) has developped a biomass fractionator to pretreat lignocellulose to yield a highly pure cellulose fraction. The biomass fractionator is based on sequentially treating biomass with hot water, hot alkaline solutions, and polishing the cellulose fraction with a wet alkaline oxidation step. PureVision now carries out fractionation and rapid hydrolysis testing at the bench and half-ton per day scales, with a focus on scaling up to a 20 -ton per day, fully-integrated cellulosic biorefining facility expected to break ground during the 4th quarter of 2011.

Lignol's solvent-based pre-treatment technology (www.lignol. ca) was originally developed by a former affiliate of General Electric ("GE"), and then further developed and commercialized for wood- 
pulp applications by a subsidiary of Repap Enterprises Inc. Lignol has modified the pre-treatment process and integrated it with proprietary capabilities to convert cellulose to ethanol. Lignol's process includes an expensive pre-treatment step that fractionates biomass into separate streams of cellulose, hemicellulose and lignin, enabling the company to produce a variety of high value products, including furfural, acetic acid and a trademarked lignin, known as HP-L. The successful test of the effectiveness of Novozymes' enzymes and Lignol's substrate is an important step towards establishing Lignol's first commercial project, which is to be located in the United States.

\section{Closing Remarks}

Although pretreatment technologies have been extensively studied, it has become unclear who will be the pretreatment technology 'winners'. The advantages and disadvantages of pretreatment technologies reviewed in the article are summarized in Table 1.

To develop a cost-effective pretreatment process, the following criteria should be considered: 1 ) the process requires minimized size reduction; 2) the requirement of pretreatment reagents is minimized; 3 ) the hemicellulose recovery is maximized; 4) the process does not form significant amount of inhibitors for enzyme hydrolysis and fermentation steps; and 5) the process is designed in a way to simplify the downstream processing.

\section{References}

1. Lynd L, Elamder R, Wyman C (1996) Likely features and costs of mature biomass ethanol technology. Applied Biochemistry and Biotechnology 57-58: 741-761.

2. Mosier N, Wyman C, Dale B, Elander R, Lee YY, et al. (2005) Features of promising technologies for pretreatment of lignocellulosic biomass. Bioresource Technology 96: 673-686.

3. Yang B, Wyman CE (2008) Pretreatment: the key to unlocking low-cost cellulosic ethanol. Biofuels, Bioproducts and Biorefining 2: 26-40.

4. Hsu TA, Ladisch MR, Tsao GT (1980) Alcohol from cellulose. Chemical Technology 10: 315-319.

5. Zhu Y, Pan $X(2010)$ Biomass pretreatment for cellulosic ethanol production. International Journal of Agricultural and Biological Engineering 2: 1-18.

6. Elander RT, Dale BE, Holtzapple M, Ladisch MR, Lee YY, et al. (2009) Summary of findings from the Biomass Refining Consortium for Applied Fundamentals and Innovation (CAFI): corn stover pretreatment. Cellulose 16: 649-659.

7. Li Y, Ruan R, Chen PL, Liu Z, Pan X, et al. (2004) Enzymatic hydrolysis of corn stover pretreated by combined dilute alkaline treatment and homogenization. Transactions of the ASAE 47: 821-825.

8. DuPont-Danisco, Fact Sheet. http://www.tennessee.edu/media/kits/biorefinery/ docs/ddce_fact_sheet.pdf accessed on May 31, 2011

9. Zhang B, Shahbazi A, Wang L, Diallo O, Whitmore A (2010) Alkali Pretreatment and Enzymatic Hydrolysis of Cattails from Constructed Wetlands. Am J Eng Applied Sci 3: 328-332.

10. Gupta R (2008) Alkaline pretreatment of biomass for ethanol production and understanding the factors influencing the cellulose hydrolysis. Ph.D.dissertation Auburn University.

11. Zhao Y, Wang Y, Zhu JY, Ragauskas A, Deng Y (2008) Enhanced enzymatic hydrolysis of spruce by alkaline pretreatment at low temperature. Biotechnology and Bioengineering 99: 1320-1328.

12. Carrillo F, Lis MJ, Colom X, López-Mesas M, Valldeperas J (2005) Effect of alkali pretreatment on cellulase hydrolysis of wheat straw: Kinetic study. Process Biochemistry 40: 3360-3364.

13. Kim S, Holtzapple M (2005) Lime pretreatment and enzymatic hydrolysis of corn stover. Ph. D.dissertation; Texas A\&M University.

14. Kim S, Holtzapple M (2006) Effect of structural features on enzyme digestibility of corn stover. Bioresource Technology 97: 583-591.
15. Rabelo SC, Filho RM, Costa AC (2009) Lime Pretreatment of Sugarcane Bagasse for Bioethanol Production. Applied Biochemistry and Biotechnology 153: $139-150$.

16. Xu J, Cheng JJ, Sharma-Shivappa RR, Burns JC (2010) Lime pretreatment of switchgrass at mild temperatures for ethanol production. Bioresource Technology 101: 2900-2903.

17. Sierra R, Garcia LA, Holtzapple MT (2010) Selectivity and delignification kinetics for oxidative and nonoxidative lime pretreatment of poplar wood, part III: Long-term. Biotechnology Progress 26: 1685-1694.

18. Sierra R, Granda C, Holtzapple MT (2009) Short-term lime pretreatment of poplar wood. Biotechnology Progress 25: 323-332.

19. Sierra R, Holtzapple MT, Granda CB (2010) Long-term lime pretreatment of poplar wood. Journal: DOI 10.1002/aic.12350.

20. Teymouri F, Laureanoperez L, Alizadeh H, Dale B (2005) Optimization of the ammonia fiber explosion (AFEX) treatment parameters for enzymatic hydrolysis of corn stover. Bioresource Technology 96: 2014-2018.

21. Alizadeh H, Teymouri F, Gilbert T, Dale B (2005) Pretreatment of switchgrass by ammonia fiber explosion (AFEX). Applied Biochemistry and Biotechnology 124: 1133-1141.

22. Lee JM, Jameel H, Venditti RA (2010) A comparison of the autohydrolysis and ammonia fiber explosion (AFEX) pretreatments on the subsequent enzymatic hydrolysis of coastal Bermuda grass. Bioresource Technology 101: 5449-5458.

23. Li B-Z, Balan V, Yuan Y-J, Dale BE (2010) Process optimization to convert forage and sweet sorghum bagasse to ethanol based on ammonia fiber expansion (AFEX) pretreatment. Bioresource Technology 101: 1285-1292.

24. Bals B, Rogers C, Jin M, Balan V, Dale B (2010) Evaluation of ammonia fibre expansion (AFEX) pretreatment for enzymatic hydrolysis of switchgrass harvested in different seasons and locations. Biotechnology for Biofuels 3: 1 .

25. Kim T, Lee $Y$ (2005) Pretreatment and fractionation of corn stover by ammonia recycle percolation process. Bioresource Technology 96: 2007-2013.

26. Kim T, Lee Y, Sunwoo C, Kim J (2006) Pretreatment of corn stover by low-liquid ammonia recycle percolation process. Applied Biochemistry and Biotechnology 133: $41-57$.

27. Salvi D, Aita G, Robert D, Bazan V (2010) Ethanol production from sorghum by a dilute ammonia pretreatment. Journal of Industrial Microbiology \& Biotechnology 37: 27-34.

28. Gupta R, Lee YY (2009) Pretreatment of hybrid poplar by aqueous ammonia Biotechnology Progress 25: 357-364.

29. Wyman C, Dale B, Elander RTH, Ladisch MR, Lee YY, et al. (2009) Glucose and xylose yields from switchgrass for ammonia fiber expansion, ammonia recycle percolation, dilute sulfuric acid, hot water, lime, and sulfur dioxide pretreatments followed by enzymatic hydrolysis. In the 31st Symposium on Biotechnology for Fuels and Chemicals SanFranciscoCA.

30. Kim T, Lee $Y$ (2005) Pretreatment of corn stover by soaking in aqueous ammonia. Applied Biochemistry and Biotechnology 124: 1119-1131.

31. Kim T, Lee $Y$ (2007) Pretreatment of corn stover by soaking in aqueous ammonia at moderate temperatures. Applied Biochemistry and Biotechnology 137-140: 81-92.

32. Huang H, Ramaswamy S, Tschirner U, Ramarao B (2008) A review of separation technologies in current and future biorefineries. Separation and Purification Technology 62: 1-21.

33. Zhang B, Shahbazi A, Wang L, Diallo O, Whitmore A (2010) Hot-water pretreatment of cattails for extraction of cellulose. Journal of Industrial Microbiology \& Biotechnology 38: 819-824.

34. Mosier N, Hendrickson R, Ho N, Sedlak M, Ladisch M (2005) Optimization of $\mathrm{pH}$ controlled liquid hot water pretreatment of corn stover. Bioresource Technology 96: 1986-1993.

35. Laser M, Schulman D, Allen SG, Lichwa J, Antal MJ, et al. (2002) A comparison of liquid hot water and steam pretreatments of sugar cane bagasse for bioconversion to ethanol. Bioresource Technology 81: 33-44.

36. Kim Y, Mosier NS, Ladisch MR (2008) Effect of Liquid Hot Water Pretreatment on Switchgrass Hydrolysis. In AIChE meeting, Philadelphia, PA 
Citation: Zhang B, Shahbazi A (2011) Recent Developments in Pretreatment Technologies for Production of Lignocellulosic Biofuels. J Pet Environ Biotechnol 2:111. doi:10.4172/2157-7463.1000108

37. Kim Y, Mosier NS, Ladisch MR (2009) Enzymatic digestion of liquid hot water pretreated hybrid poplar. Biotechnology Progress 25: 340-348.

38. Energy D Ethanol from straw - the INBICON biorefinery demonstration facility.

39. Yang B, Wyman CE (2004) Effect of xylan and lignin removal by batch and flowthrough pretreatment on the enzymatic digestibility of corn stover cellulose. Biotechnology and Bioengineering 86: 88-98

40. Knappert DR, Grethlein HE, Converse AO (1981) Partial acid hydrolysis of poplar wood as a pretreatment for enzymatic hydrolysis. Biotechnol Bioengin Symp 11: 67-77.

41. Lloyd T, Wyman C (2005) Combined sugar yields for dilute sulfuric acid pretreatment of corn stover followed by enzymatic hydrolysis of the remaining solids. Bioresource Technology 96: 1967-1977.

42. Zhang B, Shahbazi A, Wang L, Diallo O, Whitmore A (2011) Dilute-sulfuric acid pretreatment and cellulose conversion of cattails. In ASABE Annual Meeting, Louisville, Kentucky.

43. Yang Y, Sharma-Shivappa R, Burns JC, Cheng JJ (2009) Dilute Acid Pretreatment of Oven-dried Switchgrass Germplasms for Bioethanol Production†. Energy \& Fuels 23: 3759-3766.

44. Torget R, Himmel ME, Grohmann K (1991) Dilute sulfuric acid pretreatment of hardwood bark. Bioresource Technology 35: 239-246.

45. Nguyen Q, Tucker M, Keller F, Eddy F (2000) Two-stage dilute-acid pretreatment of softwoods. Applied Biochemistry and Biotechnology 84-86: 561-576.

46. Bura R, Mansfield S, Saddler J, Bothast R (2002) SO2-catalyzed steam explosion of corn fiber for ethanol production. Applied Biochemistry and Biotechnology 98-100: 59-72.

47. Bura R, Bothast R, Mansfield S, Saddler J (2003) Optimization of SO2 catalyzed steam pretreatment of corn fiber for ethanol production. Applied Biochemistry and Biotechnology 106: 319-335

48. Ewanick SM, Bura R, Saddler JN (2007) Acid-catalyzed steam pretreatmen of lodgepole pine and subsequent enzymatic hydrolysis and fermentation to ethanol. Biotechnology and Bioengineering 98: 737-746.

49. Kumar L, Chandra R, Chung PA, Saddler J (2010) Can the same steam pretreatment conditions be used for most softwoods to achieve good, enzymatic hydrolysis and sugar yields? Bioresource Technology 101: 7827-7833.

50. Ouyang J, Ma R, Huang W, Li X, Chen M, et al. (2011) Enhanced saccharification of $\mathrm{SO} 2$ catalyzed steam-exploded corn stover by polyethylene glycol addition. Biomass and Bioenergy DOI: 10.1016/j.biombioe.2011.01.047.

51. De Bari I, Nanna F, Braccio G (2007) SO2-Catalyzed Steam Fractionation of Aspen Chips for Bioethanol Production: Optimization of the Catalyst Impregnation. Industrial \& Engineering Chemistry Research 46: 7711-7720.

52. Abengoa Bioenergy, Abengoa Bioenergy Hybrid of Kansas, LLC (ABHK).

53. U.S. Department of Energy - Energy Efficiency and Renewable Energy Biomass Program, Concentrated Acid Hydrolysis.
54. Badger PC (2002) Ethanol from cellulose: A general review. In Trends in new crops and new uses (Janick J \& Whipkey A, eds), pp. 17-21. ASHS Press, Alexandria, VA.

55. Swatloski RP, Spear SK, Holbrey JD, Rogers RD (2002) Dissolution of Cellose with Ionic Liquids. Journal of the American Chemical Society 124: 4974-4975.

56. Graenacher C, Manufacture and Application of New Cellulose Solutions and Cellulose Derivatives Produced therefrom, US 1934/1943176.

57. Li C, Knierim B, Manisseri C, Arora R, Scheller HV, et al. (2010) Comparison of dilute acid and ionic liquid pretreatment of switchgrass: Biomass recalcitrance, delignification and enzymatic saccharification. Bioresource Technology 101 4900-4906.

58. Dadi AP, Varanasi S, Schall CA (2006) Enhancement of cellulose saccharification kinetics using an ionic liquid pretreatment step. Biotechnology and Bioengineering 95: 904-910.

59. Dadi A, Schall C, Varanasi S (2007) Mitigation of cellulose recalcitrance to enzymatic hydrolysis by ionic liquid pretreatment. Applied Biochemistry and Biotechnology 137-140: 407-421.

60. Zhao H, Jones C, Baker G, Xia S, Olubajo O, et al. (2009) Regenerating cellulose from ionic liquids for an accelerated enzymatic hydrolysis. Journal of Biotechnology 139: 47-54.

61. Lucas M, Macdonald BA, Wagner GL, Joyce SA, Rector KD (2010) Ionic Liquid Pretreatment of Poplar Wood at Room Temperature: Swelling and Incorporation of Nanoparticles. ACS Applied Materials \& Interfaces 2: 2198-2205.

62. Singh S, Simmons BA, Vogel KP (2009) Visualization of biomass solubilization and cellulose regeneration during ionic liquid pretreatment of switchgrass. Biotechnology and Bioengineering 104: 68-75.

63. March J (1992) Advanced Organic Chemistry. 4th edn J. Wiley and Sons, New York.

64. Wan Y, Chen P, Zhang B, Yang C, Liu Y, et al. (2009) Microwave-assisted pyrolysis of biomass: Catalysts to improve product selectivity. Journal of Analytical and Applied Pyrolysis 86: 161-167.

65. Zhao H, Holladay JE, Brown H, Zhang ZC (2007) Metal Chlorides in lonic Liquid Solvents Convert Sugars to 5-Hydroxymethylfurfural. Science 316: 1597-1600.

66. Liu C, Wyman C (2006) The enhancement of xylose monomer and xylotriose degradation by inorganic salts in aqueous solutions at $180^{\circ} \mathrm{C}$. Carbohydrate Research 341: 2550-2556.

67. Yu Q, Zhuang X, Yuan Z, Qi W, Wang Q, et al. (2011) The effect of meta salts on the decomposition of sweet sorghum bagasse in flow-through liquid hot water. Bioresource Technology 102: 3445-3450

68. Liu L, Sun J, Cai C, Wang S, Pei H, et al. (2009) Corn stover pretreatment by inorganic salts and its effects on hemicellulose and cellulose degradation. Bioresource Technology 100: 5865-5871.

69. Liu L, Sun J, Li M, Wang S, Pei H, et al. (2009) Enhanced enzymatic hydrolysis and structural features of corn stover by $\mathrm{FeCl} 3$ pretreatment. Bioresource Technology 100: 5853-5858. 